\title{
Human age estimation based on pulp volume of canines for chronological age estimation: Preliminary research
}

\author{
Septian Rahmat Hidayat*, Fahmi Oscandar*, Yuti Malinda**, Yurika Ambar Lita*** \\ *Department of Dentomaxillofacial Radiology, Faculty of Dentistry, Universitas Padjadjaran, \\ Indonesia \\ **Department of Oral Biology, Faculty of Dentistry, Universitas Padjadjaran, Indonesia \\ ***Biomedical Sciences Magister Programme, Faculty of Medicine, Universitas Padjadjaran, \\ Indonesia
}

\begin{abstract}
Introduction: Age estimation has an important role in the process of human identification, and it needs to be done efficiently fast and accurate. Age estimation based on pulp cavity volume of canines was referring to the theory that the apposition of secondary dentin during human life could be an age indicator. The study used a CBCT image, and ITK-SNAP software which gave a fast and accurate measurement process. This study was aimed to estimate age based on pulp volume of for chronological estimation. Methods: Forty-one canine teeth from Cone Beam Computed Tomography (CBCT) 3D image sample from RSGM Unpad segmented into dental pulp and enamel were prepared for measurement of pulp volume using ITK SNAP volumetric software. Descriptive analyses for pulp volume and regression equations were generated from regression analysis of pulp volume and tested for age estimation. Results: Dentin Thickness were found to increase from adolescence age range until adulthood age range. Logarithmic regression between pulp volume and was statistically significant $(p<0,001)$. The coefficient of determination $\left(R^{2}\right)$ was 0.753 with a standard deviation of 8.421. Mathematics model for estimating age was AGE $=79.523-(18.194 x \ln$ (Pulp Volume)). The result of this study showed that the pulp cavity was decreasing with the increase of age and increasing dentin thickness. The equation was used in the same sample. Between chronological age and estimated age, there are some differences with SEE around 8.4 years following the regression result of R square was $75.3 \%$. The rest of the sample (24.7\%) have a big difference, and this could be affected by modifying variables such as occlusal force and human error measurement procedures. Conclusion: The study showed that the age could be estimated by the pulp volume of canines.
\end{abstract}

Keywords: Age estimation, pulp volume, canine, ITK-SNAP, CBCT

P-ISSN 1979-0201, e-ISSN 2549-6212 Available from:http://jurnal.unpad.ac.id/pjd/article/view/19302

DOI: http://dx.doi.org/10.24198/pjd.vol30no3.19302

Submission: Aug 22, 2017; Reviewed: Apr 12, 2018; Resubmit for review: Aug 7, 2018; Accepted: Oct 5, 2018; Published online: Nov 30, 2018

Corresponding author: Yurika Ambar L. Biomedical Sciences Magister Programme, Faculty of Medicine, Universitas Padjadjaran Jalan Professor Eyckman 38, Bandung, Indonesia 40161. Phone: +6282121950530; Email: yurika.lita@fkg.unpad.ac.id. 


\section{INTRODUCTION}

Forensic odontology plays an essential role in the identification of those people who cannot be identified. The teeth may be used and provide information regarding identity. Dental professionals play a necessary part in dental records so that legal authorities may recognise malpractices, negligence, fraud child abuse and also, identify an individual.

Age is one factor important in every aspect of life, in clinical practice; legal research and court. ${ }^{2}$ Identification of age can help in determining personal identities such as physical examination using anthropometric measurements, skeletal maturation, estimation of dental age with growth and the ageing process that occurs. ${ }^{3}$ Parameters between age and secondary dentin that can be used to estimate the age of the subject, one of the measurement is pulp volume which is an accurate and easy method for morphometric parameters. ${ }^{4}$ require great technical expertise, and have proved inexact in the estimation of ages over 50 years. Certain dental methods investigate the apposition of secondary dentine, in the study of tooth cross-sections, and X-rays to study width, height, and pulp area. The primary author previously proposed a method of estimating the age of a living person based on the pulp/tooth ratio (PTR Secondary dentin is formed continuously in pulp with a slow phase as long as human life. Pulp volume will be decreased because secondary dentin formed inside the pulp. The decreasing of pulp caused by secondary dentine can be measured for age estimation because of its continuity in human life. ${ }^{5}$ Gottlieb et al. correlated age changes in dentition to estimate the age and apposition of secondary dentin to age was established by Bodeckar. ${ }^{6-8}$

The pulp volume can be studied using radiographs and a cross section of the tooth root. Considering the distortion and two dimensional (2D) projection errors with periapical and panoramic radiographs to assess the pulp and tooth area, Cone beam computed tomography (CBCT) images were utilized in the present work. CBCT images were described as the most exact method to measure the pulp volume. ${ }^{6}$ CBCT gives an alternative investigation with the noninvasive approach because tooth extraction is not needed. ${ }^{9}$ Canines used in research because it has some advantages among the teeth. Canines perfectly formed in the late mixed dentition phase and can be used as an age indicator for adolescence and adult age. Canines conserved in any dental treatment because of functional and aesthetic reasons. Canines are single-rooted teeth which will make easier process in the research to calculate its pulp volume.

The volume of the pulp can be acquired by the segmentation process in ITK-SNAP. ITKSNAP is open-source software that can open a $\mathrm{CBCT}$ image and measure the pulp volume with the segmentation process. ITK-SNAP software will calculate the volume automatically. The pulp volume and the actual age will be analysed with regression to make the equations for age estimation. The purpose of this study was to determine the applicability of pulp volume canine for age estimation.

\section{METHODS}

The analysis correlational study design used for this research. Samples of canine teeth from cone beam computed tomography (CBCT) images were observed and collected. The population of this research consist of 19 males and 22 females aged between 13-73 years old. The inclusion criteria for canine were without caries and restoration, normal morphology, and absence metal object such as a dental bracket. In this study fortyone canine teeth that were obtained from Cone Beam Computed Tomography (CBCT) from Dental Hospital of Faculty of Dentistry Universitas Padjadjaran.

The study used secondary data of CBCT image sample from Dental Hospital of Faculty of Dentistry Universitas Padjadjaran. Cone Beam Computed Tomography (CBCT) is an imaging technology for teeth and bone structure that can produce a three-dimension image. CBCT technology can capture both the teeth and all its structure. ${ }^{9}$ The tool used in this research was an open-source software ITK-SNAP version 3.6.0 to calculate the pulp volume. All the collected CBCT were exported as DICOM datasets. These data were then imported into a 3D image automatic segmenting (Figure 1 and 2) and voxel-counting software ITK-Snap for the calculation of the 


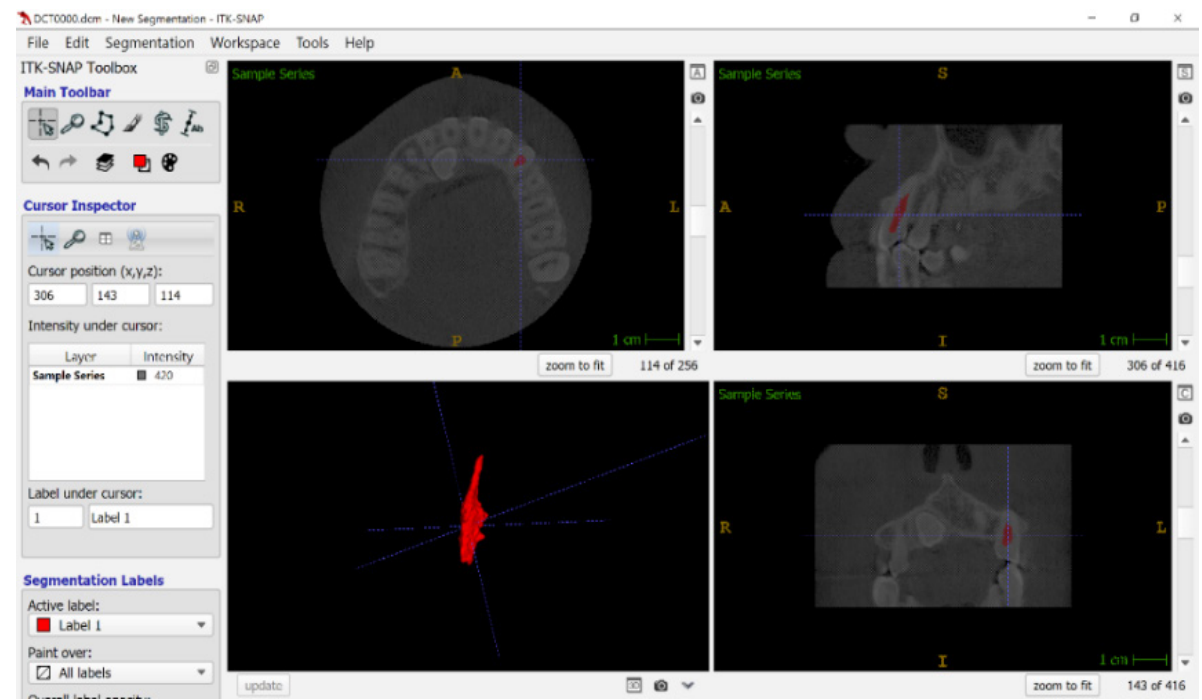

Figure 1. Segmented pulp volume from ITK-SNAP

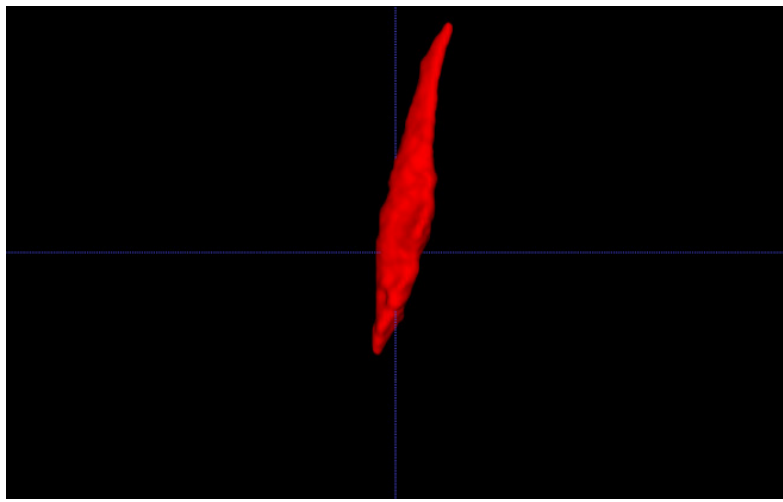

Figure 2. Segmentation 3D view

volume of the canine pulp chamber. ${ }^{10}$

Dental pulp was automatically segmented using active contour segmentation mode (Figure 2). Pulp volume measurement was analysed to find out the regression formula of age estimation. IBM SPSS Statistics 24 software to make regression analysis, and CD-ROM for saving the data. Regression analysis between chronological age and pulp volume was done in IBM SPSS Statistics. Model mathematic from regression was reproduced in the same sample. This research has been approved by The Health Research Ethics Committee of Faculty of Medicine, Universitas Padjadajaran with the registration number of No.857/UN6.C10/PN/2017.

\section{RESULT}

Pulp volume measurement based on chronological age are shown in Figure 3. The results of pulp volume and chronological age data were

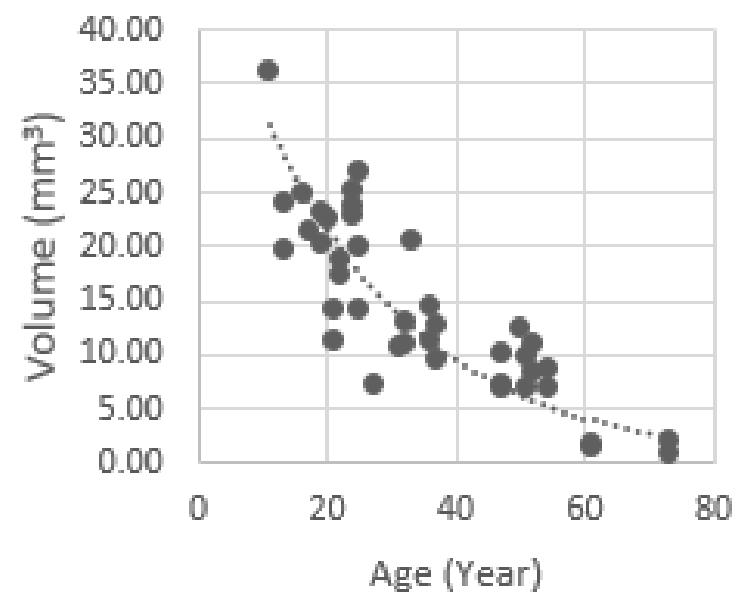

Figure 3. Pulp volume and chronological age

determined by generating regression equations obtained from the regression analysis. The age and volume data obtained through the ITK-SNAP application were regressed using the IBM SPSS Statistic 24 application and produced equation as follows:

$$
\text { Age }=79.523-(18.194 \times \ln (\text { Pulp Volume }))
$$

Regression analyses revealed R Square of 0.753 or $75 \%$ which means the equation generated will match the age and pulp volume data. ANOVA test results show that $p<0.001$ so the results were statistically significant.

The estimated age was then compared to the chronological age to tested accuracy of the predicted age using the pulp volume. Some of the data deviant and exceeds the standard 


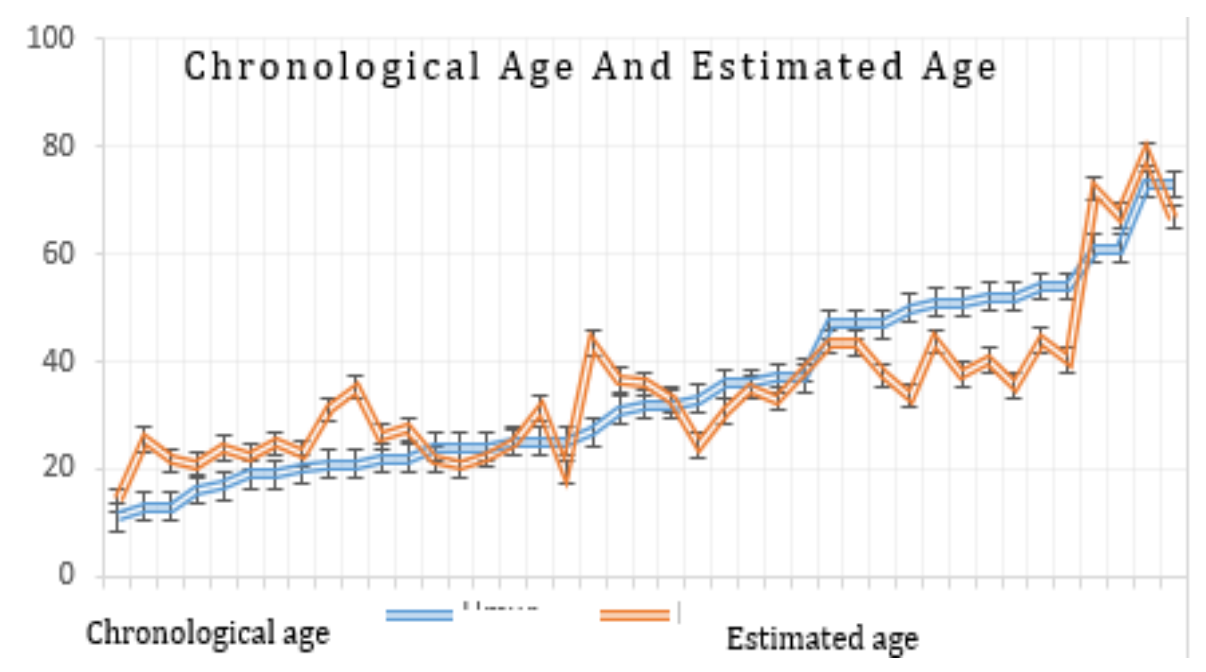

Figure 4. The differences in chronological age and estimated age

deviation shown in figure 5 where $\mathrm{R}^{2}$ is $75.3 \%$ and Standard Error of Estimate (SEE) 8.4 years which means that only $75.3 \%$ of the data can be explained by regression formulas and does not deviate from standard deviation. The remaining data as much as $24.7 \%$ looks deviant can be caused by the quality of the image and errors in the measurement procedure. Result of this study showed that there was an increase of dentin height in from adolescence age range into adult age range (Figure 4 ).

\section{DISCUSSION}

Chronological is the age of an individual expressed as the time that has elapsed since birth. ${ }^{11}$ Chronological age can be identified using the date of birth. ${ }^{12}$ There are two methods to determine the chronological age besides using the date of birth which is the growth of bone and dentin at the pulp chamber. ${ }^{13}$ Formation of dentin proceeds throughout life, dentin formation before completion of the crown is called primary dentin. This process is followed by the formation of secondary dentin. The same odontoblast that formed the primary dentin remain functional and produce secondary dentin. With advancing age in functioning teeth, dentin is deposited diffusely along the inner walls and lead to smaller pulp chambers and canals. This type of dentin is termed physiological secondary dentin and exhibits slow and gradual deposition that increases after the age of 35 to 40 years. ${ }^{14}$

Studies used secondary dentine growth and pulp volume reduction factor but were measured by $2 \mathrm{D}$ radiology images such as panoramic and intraoral. Research using 3D images such as CBCT has apparent advantages because the pulp cavity is volumetric and the spread of dentine growth is not always the same. This study uses pulp volume as a variable due to secondary dentine growth as an indicator of age increase occurring directly in the pulp cavity, whereas the total tooth volume is not affected by dentine growth and is affected by dental attrition. The attrition of the tooth has many factors and varies among individuals, so it is not used as a variable in this study, in contrast to previous studies conducted using the ratio of the dental pulp volume and overall dental volume, ${ }^{15-17}$ dentin height used to detect dentin deposition in roof dental pulp. The previous study had found that dentinal deposition occurs in two places, the roof of the pulp chamber roof and the base of the pulp chamber.

ANOVA statistical test results showed that the regression results were statistically significant with $p=0.000<0.001$. The results of statistical tests with these figures show that the regression model is good enough to be used to estimate the age based on pulp volume. The ITK-SNAP application has good efficiency and accuracy to measure the pulp volume of the canine teeth. Canine selected teeth in this research because considered as the key teeth for identification and the last teeth extracted to be related to ageing. ${ }^{18}$ In the study conducted by Kumar et al. suggested that the size of pulp volume in the canines to age is more accurate ${ }^{19}$, and the canines have the 
longest roots, so it has high resistance. ${ }^{20}$

The coefficient of determination or $\mathrm{R}$ square $\left(R^{2}\right)$ in this study was as much as 0.753 or 75.3\%. In a previous study conducted by Pu et al. ${ }^{21}$ suggested that estimated age based on first molar pulp chamber volume, the R square was 0.564 or $56.4 \%$. Moderator variable that may affect this research are mastication force, a significantly decreased amount of secondary dentin has been described in impacted teeth, suggesting that functional forces of occlusion promote the deposition. Deposition within the pulp chamber often is not totally uniform. In posterior teeth, the greatest deposition is seen on the pulpal flow to a lesser extent on the roof and least on the sidewalls. Therefore, along the age, pulp chamber decreases significantly in height but extensively in width. ${ }^{14}$ This study based on adolescence age range into adult age range showed a significant decrease of pulp volume from the whole of walls. Measurement of the pulp volume of canine tooth as defending teeth in adults was applicable for chronological age estimation.

\section{CONCLUSION}

Chronological age can be estimated by the equations of the canine pulp volume of canines, because along the age, the pulp volume was decreasing.

\section{REFERENCES}

1. Gupta S, Agnihotri A, Chandra A, Gupta OP. Contemporary practice in forensic odontology. J Oral Maxillofac Pathol. 2014;18(2):244-250. DOI: 10.4103/0973-029X.140767.

2. Priyadarshini C, Puranik MP, Uma SR. Dental Age Estimation Methods: A Review. Int J Adv Health Sci, 2015;1(12):19-25.

3. Simon S, Smith AJ, Berdal A, Lumley PJ, Cooper PR. The MAP Kinase Pathway Is Involved in Odontoblast Stimulation via p38 Phosphorylation. J Endod. 2010;36(2):256-9. DOI: 10.1016/j.joen.2009.09.019.

4. Cameriere R, Brogi G, Ferrante L, Mirtella D, Vultaggio C, Cingolani M, et al. Reliability in age determination by pulp/tooth ratio in upper canines in skeletal remains. J Forensic Sci. 2006;51(4):861-4. DOI: 10.1111/j.1556- 4029.2006.00159.x.

5. Tardivo D, Sastre J, Ruquet M, Thollon L, Adalian P, Leonetti G, et al. Three-dimensional Modeling of the Various Volumes of Canines to Determine Age and Sex: A Preliminary Study. J Forensic Sci. 2011;56(3):766-70. DOI: 10.1111/j.1556-4029.2011.01720.x.

6. Kumar S, Deepthi, Setty JV. Age Estimation Using Pulp Chamber Volume of First Molars from Cone Beam Computed Tomography Images in Indian Population. Int J Sci Res 2013;5(4):2421-5.

7. Brkić $H$, Miličević $M$, Petrovečki M. Forensic determination of dental age of adults. Acta Stomatol Croat 2008;42:267-72.

8. Bodeckar CF. A consideration of some of the changes in the teeth from young to old age. Dental Cosmos. 1925;67:543-9.

9. Maret D, Peters OA, Dedouit F, Telmon N, Sixou M. Cone-Beam Computed Tomography: A useful tool for dental age estimation? Med Hypotheses. 2011;76(5):700-2. DOI: 10.1016/j.mehy.2011.01.039.

10. Yushkevich P, Piven J, Cody H, Ho S, Gee JC, Gerig G. User-guided level set segmentation of anatomical structures with ITK-SNAP. Neuroimage. Neuroimage. 2006; 31(3): 111628. DOI: 10.1016/j.neuroimage.2006.01.015.

11. Mosby. Mosby's Medical Dictionary. $8^{\text {th }}$ ed. St. Louis: Elsevier Health Sciences; 2009.

12. Ogodescu AE, Ogodescu A, Szabo K, Tudor A, Bratu E. Dental Maturity-a biologic indicator of chronological age: Digital radiographic study to assess Dental age in Romanian children. Int J Biol Biomed Eng. 2011;5(1):32-40.

13. Chaillet N, Willems G, Demirjian A. Dental Maturity in Belgian Children Using Demirjian's Method and Polynomial Functions: New Standard Curves for Forensic and Clinical Use. J. Forensic Odontostomatol. 2004;22(2):1827.

14. Neville B, Damm DD, Allen C, Chi A. Oral and Maxillofacial Pathology. $4^{\text {th }}$ ed. Philadelphia: Saunders-Elsevier; 2015.

15. Pinchi V, Pradella F, Buti J, Baldinotti C, Focardi $M$, Norelli GA. A new age estimation procedure based on the 3D CBCT study of the pulp cavity and hard tissues of the teeth for forensic purposes: A pilot study. J Forensic Leg Med; 36: 150-7. DOI: 10.1016/j.jflm.2015.09.015. 
16. Sakuma A, Saitoh H, Suzuki Y, Makino $Y$, Inokuchi G, Hayakawa M, Yajima D, Iwase H. Age Estimation Based on Pulp Cavity to Tooth Volume Ratio Using Postmortem Computed Tomography Images. J Forensic Sci. 2013;58(6):1531-5. DOI: 10.1111/15564029.12175.

17. Star $H$, Thevissen $P$, Jacobs $R$, Fieuws $S$, Solheim T, Willems G. Human Dental Age Estimation by Calculation of Pulp - Tooth Volume Ratios Yielded on Clinically Acquired Cone Beam Computed Tomography Images of Monoradicular Teeth. J Forensic Sci. 2011;56 Suppl 1:S77-82. DOI: 10.1111/j.15564029.2010.01633.x.

18. Verma AK, Kumar S, Rathore S, Pandey A. Role of dental expert in forensic odontology. Natl J Maxillofac Surg. 2014;5(1):2-5. DOI:
10.4103/0975-5950.140147.

19. Kumar NN, Panchaksharappa MG, Annigeri RG. Psychosomatic disorders: An overview for oral physician. J Indian Acad Oral Med Radiol. 2016;28:24-9. DOI: 10.4103/09721363.189979.

20. Lee SM, Oh S, Kim J, Kim YM, Choi YK, Kwak $\mathrm{HH}$, et al. Age estimation using the maxillary canine pulp / tooth ratio in Korean adults: A CBCT buccolingual and horizontal section image analysis. J Forensic Radiol Imaging. 2017;9:1-5. DOI: 10.1016/j.jofri.2016.12.001. 21. Ge ZP, Ma RH, Li G, Zhang JZ, Ma XC. Age estimation based on pulp chamber volume of first molars from cone-beam computed tomography images. Forensic Sci Int. 2015;253:133.e1-7. DOI: 10.1016/j. forsciint.2015.05.004. 